Article

\title{
Chemical Composition and Micro Morphology of Golden Laminae in the Wall Painting "La Maestà" by Simone Martini: A Study by Optical Microscopy, XRD, FESEM-EDS and ToF-SIMS
}

\author{
Andrea Atrei ${ }^{1, *(\mathbb{D}}$, Andrea Scala ${ }^{2}$, Marco Giamello ${ }^{2}$, Marianna Uva ${ }^{3}$, Riccardo Maria Pulselli ${ }^{4}$ \\ and Nadia Marchettini ${ }^{5}$ \\ 1 Dipartimento di Biotecnologie, Chimica e Farmacia, Università di Siena, 53100 Siena, Italy \\ 2 Dipartimento di Scienze Fisiche, della Terra e dell'Ambiente, Università di Siena, 53100 Siena, Italy \\ CREA (Centro Ricerca Energia e Ambiente), Colle di Val d'Elsa, 53034 Siena, Italy \\ Santa Chiara Lab, Università di Siena, 53100 Siena, Italy \\ 5 Dipartimento di Scienze Fisiche, della Terra e dell'Ambiente, Università di Siena, 53100 Siena, Italy \\ * Correspondence: atrei@unisi.it
}

Received: 16 July 2019; Accepted: 13 August 2019; Published: 21 August 2019

\begin{abstract}
The chemical characterization of gilding decorations in works of art is fundamental in order to elucidate the techniques and materials used by the artists. In the present work we investigated by a combination of bulk and surface sensitive methods the composition and micro stratigraphy of the gilding laminae in the wall painting of the 14th century "La Maestà", the masterpiece of Simone Martini. The aim of this study was to determine the composition of the gilding leaves and of the adhesive organic materials used to glue the metallic decorations to the wall painting. Due to the altered state of the samples we could not univocally identify the nature of the adhesive materials. Time of flight secondary ion mass spectrometry measurements showed that the gilding layers consisted of a gold leaf which was laid either directly on a preparation layer or on a tin lamina. The high sensitivity of ToF-SIMS and its spatial resolution allowed us to find traces of silver in the gold leaves and in the tin laminae which were not revealed by energy dispersive X-ray analysis.
\end{abstract}

Keywords: cultural heritage; surface analysis; wall paintings; gilding; FESEM-EDX; ToF-SIMS

\section{Introduction}

For gilding, that is the decoration of ancient works of art (wooden panels, wall paintings, metallic objects), pure gold, gold alloys (with copper or silver) as well as composite laminae of gold and silver (the so called "oro di metà") were used [1-6]. In some cases, the gold leaves were laid on a thicker tin lamina [1,2]. Gold leaves were prepared by hammering gold coins until extremely thin foils (typical thickness: 1 to 5 microns) were obtained [7]. The most commonly used methods for applying gold decorations on wall paintings were the "a guazzo" (water gilding) or the "a missione" (mordant gilding) techniques. In the "a guazzo" technique, the gold or composite metallic leaves were stuck to the surface by means of a protein-based binder mixed with "bole", a mixture of clays, iron oxides and hydroxides. In the "a missione" technique, siccative oils (typically linseed oil), mixed with lead compounds as drying agents, were used to glue the metal foils [1,4]. The chemical characterization of the gilding layers (pure gold, alloys or composite laminae) and of the adhesives used to glue the metallic leaves are essential in order to get information about the materials and techniques employed by the artist. The chemical investigation of the gilding decorations, in walls as well as in wooden panel paintings, is challenging since both the inorganic and the organic components must be analyzed. 
For this purpose, a combination of several microscopy and spectroscopy techniques is needed. In the present work, we investigated by optical microscopy (OM), field emission scanning electron microscopy (FESEM) coupled with energy dispersive X-ray analysis (EDX), micro X-ray diffraction (XRD) and time of flight secondary ion mass spectrometry (ToF-SIMS) microsamples of the gilding decorations from the wall painting of the beginning of the 14th century, "La Maestà" by Simone Martini (Figure 1). ToF-SIMS is a particularly suitable tool to investigate samples from works of art [8-11]. This mass spectrometry, surface sensitive technique allows one to analyze simultaneously, on the same sample, both the inorganic and organic components. Moreover, images of the distribution of secondary ions over the analyzed surface (chemical maps) can be obtained. The aim of this study was to determine the composition of the gilding leaves and of the materials used to glue the metallic laminae to the wall painting and the preparation layer over which the gilding leaves were laid. The combined use of these techniques permitted us to determine the stratigraphy and composition of the various layers of the microsamples. In particular, the high sensitivity and lateral resolution of ToF-SIMS were exploited to detect metal impurities in the gilding decorations. The detection of trace elements offers the possibility to identify the provenance of materials and the techniques used to make a work of art.

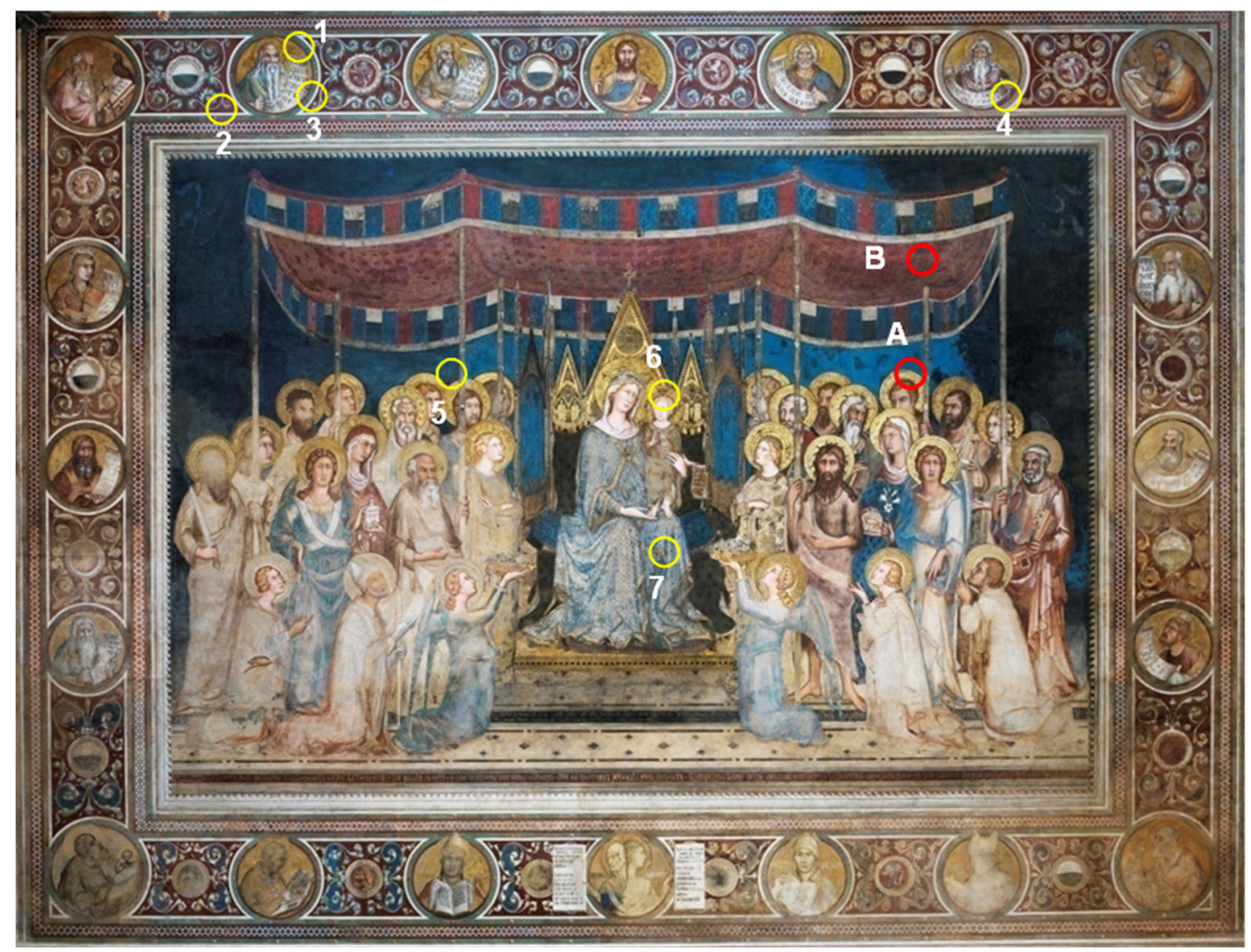

Figure 1. Wall painting "La Maestà" by Simone Martini. The sampling points are marked with yellow and red circles. The results of the analysis presented here are for sample A (halo of St. Taddeus, middle right of the painting) and sample B (decoration of the canopy, top right of the painting).

\section{Materials and Methods}

\subsection{OM Observations}

Thin sections of microfragments cut perpendicularly to the surface were observed with a polarized light microscope (LEICA DMRXP) equipped with HP PL Fluotar objective lenses, a digital reflex camera and relative software for image acquisition, transmitted and reflected light sources. 


\subsection{FESEM-EDX Measurements}

A field emission scanning electron microscope (FESEM) SIGMA VP Zeiss, Germany equipped with a system for EDX spectroscopy (Oxford Instruments, INCA x-sight 7378, Abington, UK) was used. Images were recorded by collecting backscattered electrons. EDX spectra were measured with an energy of the primary electron beam of $20 \mathrm{keV}$. Samples were coated with graphite (Balt-tec SCD 050 sputter-coater, Scotia, NY, USA) in order to prevent sample charging.

\subsection{Micro XRD Measurements}

A powder X-ray diffractometer with Bragg-Brentano geometry (Philips X'Pert PRO PW 3040/60 with X'Celerator PW 3015 detector, Almelo, The Netherlands) equipped with a multiple purpose sample stage (MPSS) for massive specimens and mono-capillary collimator tube was used. This instrument allows investigating very small samples and/or elliptical areas on thin sections with minor axis length of $100 \mu \mathrm{m}$. Diffractograms were collected with the $\mathrm{Cu} \mathrm{K} \alpha$ radiation, in a 3-70 $2 \theta$ range and a step of $0.017^{\circ}$.

\subsection{ToF-SIMS Measurements}

A TRIFT III instrument (Physical Electronics, Chanhassen, MN, USA) with a gold liquid metal ion gun as the primary ion source was used for the ToF-SIMS measurements. The primary ion beam energy was $22 \mathrm{keV}$ and a typical ion current of $600 \mathrm{pA}$, respectively. ToF-SIMS spectra were collected selecting $\mathrm{Au}^{+}$primary ions. The spectra were measured in bounced mode with a typical mass resolution, $\mathrm{m} / \Delta \mathrm{m}$, around 2000. The spectra were recorded within static conditions keeping the dose of primary ions below $10^{12}$ ions $/ \mathrm{cm}^{2}$. An electron gun was used to neutralize the positive charging of the samples. The $m / z$ scale was calibrated using the mass peaks of $\mathrm{CH}_{3}{ }^{+}, \mathrm{Na}^{+}, \mathrm{C}_{2} \mathrm{H}_{3}{ }^{+}$and $\mathrm{C}_{3} \mathrm{H}_{5}{ }^{+}$.

\subsection{Sampling Points and Sample Preparation}

"La Maestà" by Simone Martini is a wall painting, covering an area of ca. $110 \mathrm{~m}^{2}$, on the northern east wall of the "Sala del Mappamondo" in the city hall in Siena. This artwork, completed in 1315, was subsequently modified by Simone Martini in 1321. The "Maestà", the masterpiece of Simone Martini, has been studied by art historians ever since for the style, chronology, commissioning and political meanings [12,13].

Samples were collected in the points marked by circles in Figure 1 during the cleaning campaign of the wall painting in 2017, in agreement with the superintendency and the restorer. The results shown here are for the samples of type A and B, taken from the regions marked with red circles in Figure 1. The samples are representative of two types of gilding: gold leaf on the preparation layer (sample A) and gold leaf laid on a thicker tin lamina (sample B). The gold leaf directly applied on the preparation layer was used for the finer details, like the halos of saints, whereas decorations with larger thickness, like the canopy on the top right part of the painting, were made by using gold leaf on a tin lamina.

The samples embedded in epoxy resin (Epofix) were cut perpendicularly to the sequence of layers to obtain two specular parts of each sample. One part was glued on a glass slide and polished until a thickness of $30 \mu \mathrm{m}$ was reached for the OM observation as thin section. The OM of thin sections allows to get information about the thickness and colours of the layers as well as the mineralogical characterization of the phases presents [14]. The other part of the sample was polished and cut by means of a microtome (Ultratome, LKB, Bromma, Sweden) to obtain as much as possible flat and free of contamination surfaces for the ToF-SIMS measurements [15].

\section{Results}

The OM and FESEM images of the sample A are shown in Figure 2a. The OM image of the thin section shows a preparation layer with an average thickness of ca. $150 \mu \mathrm{m}$. The grains in this layer were identified as minium $\left(\mathrm{Pb}_{3} \mathrm{O}_{4}\right)$ and yellow ochres on the basis of their appearance with transmitted 
polarized light. The results of the OM observations were confirmed by the EDX results. On top of this layer, which works as the "bole" layer in the typical "a guazzo" technique, the gold lamina (with an average thickness below $5 \mu \mathrm{m}$ ) can been seen. This lamina is visible as a bright strip at one edge of the sample in the FESEM image (Figure 2b). The thickness of the metallic lamina ranges from 2 to $5 \mu \mathrm{m}$. For other samples of this type (i.e., a gold leaf on a preparation layer), FESEM images show that only some residues of the gold leaf are present. The signals of other metals, such as copper or silver, were not detectable above the noise level in the EDX spectra measured on the gold leaf (Figure 2b). Hence, the EDX analysis rules out that the gilding leaf is a copper-gold or copper-silver alloy or a composite lamina of gold and silver foils as recently found in other gilding decorations [6]. The composition of the preparation layer as determined by EDX (Table 1) is similar to that of the preparation layer for the metal decorations in the wall paintings by Giotto in the Scrovegni Chapel [2].

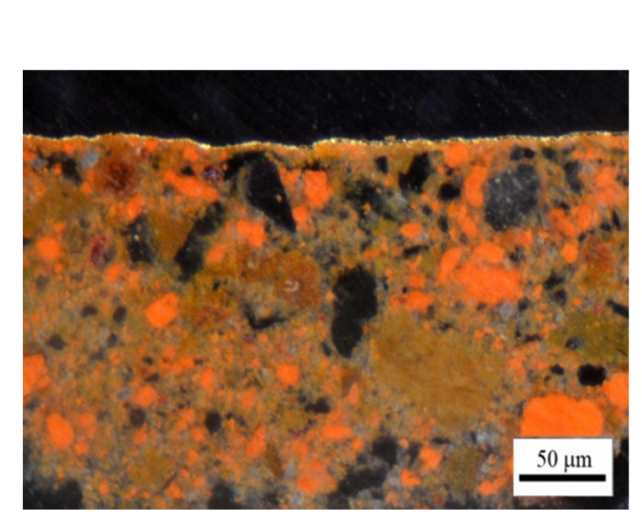

(a)

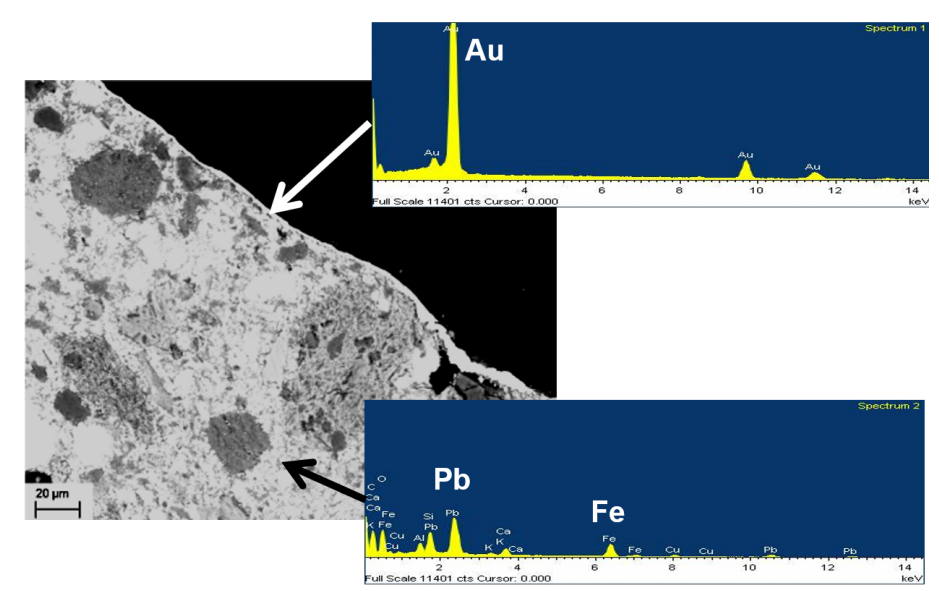

(b)

Figure 2. (a) Optical microscopy (OM) image of the thin section of sample A, reflected light, dark field. (b) Field emission scanning electron microscopy (FESEM) image of sample A and energy dispersive X-ray analysis (EDX) spectra measured on the gold leaf (spot analysis) and on the preparation layer (analyzed area $50 \times 50 \mu \mathrm{m}^{2}$ ). The metallic leaf is visible as bright region on the preparation layer. In the preparation layer grains of various materials appear with different levels of grey.

Table 1. Elemental analysis of the preparation layer of sample A as determined by EDX. The analysis was performed on an area large enough to represent an average composition.

\begin{tabular}{cc}
\hline Element & Atomic \% \\
\hline $\mathrm{Fe}$ & 28 \\
$\mathrm{Si}$ & 26 \\
$\mathrm{~Pb}$ & 16 \\
$\mathrm{Al}$ & 13 \\
$\mathrm{Ca}$ & 9 \\
$\mathrm{Cu}$ & 6 \\
$\mathrm{~K}$ & 2 \\
\hline
\end{tabular}

In the preparation layer relatively high concentrations of iron and lead were found. These results are consistent with the micro XRD measurements which show the presence of minium $\left(\mathrm{Pb}_{3} \mathrm{O}_{4}\right)$ and white lead $\left(2 \mathrm{PbCO}_{3} \mathrm{~Pb}(\mathrm{OH})_{2}\right)$ (Figure 3). The peaks of yellow ochres are too weak to be detectable in the diffractogram. Copper, which was detected by EDX, is probably present as copper resin, a drying agent used in the "a missione" technique [1]. 


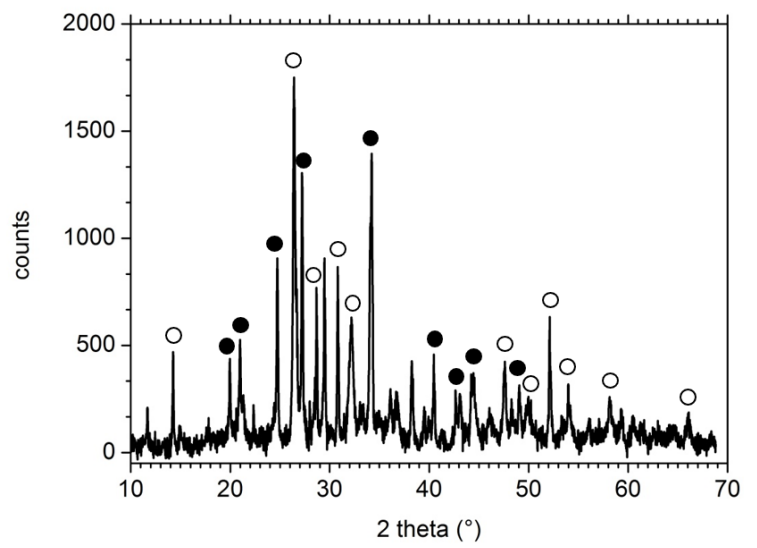

Figure 3. Diffractogram of the preparation layer of sample A. The peaks of minium $\left(\mathrm{Pb}_{3} \mathrm{O}_{4}\right)$ and white lead $\left(2 \mathrm{PbCO}_{3} \mathrm{~Pb}(\mathrm{OH})_{2}\right)$ are marked by empty and filled circles, respectively.

The whole ToF-SIMS spectrum of sample A (not shown), measured on a $500 \times 500 \mu \mathrm{m}^{2}$ area, including both the gold leaf and the preparation layer, exhibits peaks of hydrocarbon fragments having $m / z$ values close to those of the elements detected by EDX. For instance, $\mathrm{C}_{2} \mathrm{H}_{3}{ }^{+}\left(\mathrm{m} / z\right.$ 27.02) and $\mathrm{Al}^{+}(\mathrm{m} / \mathrm{z}$ 26.98), $\mathrm{C}_{3} \mathrm{H}_{3}{ }^{+}\left(\mathrm{m} / \mathrm{z}\right.$ 39.02) and $\mathrm{K}^{+}\left(\mathrm{m} / z\right.$ 38.96), $\mathrm{C}_{3} \mathrm{H}_{4}{ }^{+}\left(\mathrm{m} / \mathrm{z}\right.$ 40.03) and $\mathrm{Ca}^{+}(\mathrm{m} / \mathrm{z} 39.96)$. These peaks of hydrocarbon ion fragments are mainly due to surface contamination of the sample during cutting and handling. ToF-SIMS is a surface sensitive technique, thus even relatively small amounts of impurities in the outermost region of a sample are detectable. The peaks of the isotopes of $\mathrm{Cu}^{+}(\mathrm{m} / z 62.9$ and 64.9) and of $\mathrm{Pb}^{+}(\mathrm{m} / z$ 206.0, 207.0 and 298.0) are observed, in agreement with the EDX results. The peak of $\mathrm{Au}^{+}(\mathrm{m} / z$ 196.9) is also detectable in the spectra (Figure 4a). The location of the gold lamina over the sample cross section was found by acquiring maps of the lateral distribution of the gold signal. The peaks of $\mathrm{Ag}(\mathrm{m} / \mathrm{z} 106.9$ and 108.9) were observed when the analyzed area was reduced and localized over the gold lamina (Figure 4a). Despite the weak signal of silver, the overlay of the Au and Ag maps indicates that the silver is localized mostly within the zone of the gold lamina (Figure $4 \mathrm{~b}$ ). It is not possible to quantify the concentration of silver in the gold leaf. However, an upper limit of ca. $1 \mathrm{at} \%$ to the silver concentration is a reasonable estimation since the signal of silver was not detectable by EDX [16].

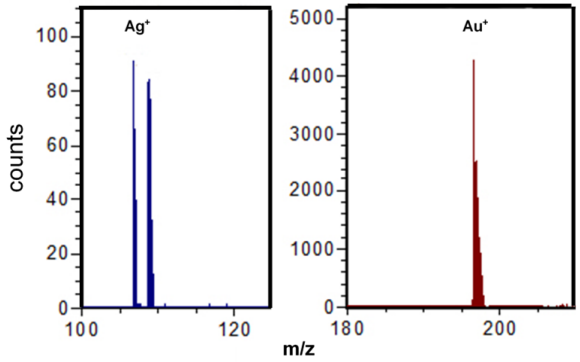

(a)
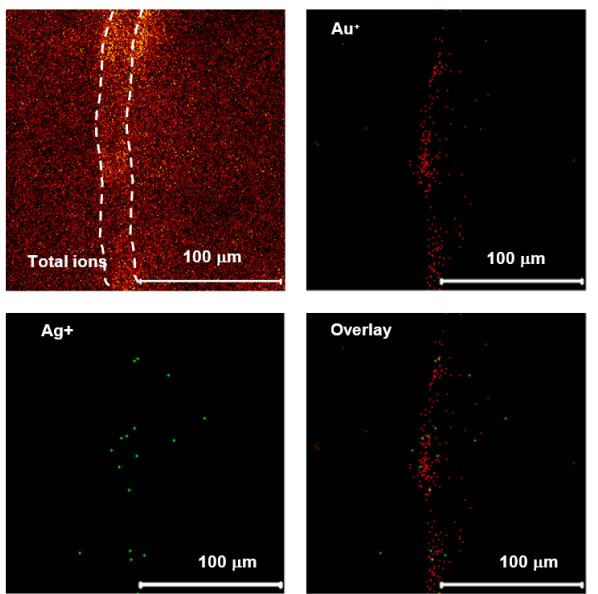

(b)

Figure 4. (a) Time of flight secondary ion mass spectrometry (ToF-SIMS) mass spectra of the $\mathrm{m} / \mathrm{z}$ regions of silver and gold for sample A. (b) Maps showing total ions, $\mathrm{Au}^{+}$(red), $\mathrm{Ag}^{+}$(green) distributions. The dashed white lines mark the zone of the gold leaf. On the left of this zone there is the embedding resin and on the right the preparation layer. The overlay of the Ag and Au ion distributions is shown in the last image. The total count rates are 80 for $\mathrm{Au}$ and 10 for Ag. 
Hence, ToF-SIMS measurements confirm that the gilding layer consists essentially of pure gold with traces of silver. Golden leaves were typically obtained by hammering coins which were made of pure gold [1,7] and the use of leaves of pure gold is not surprising taking into account the importance and the wealth commissioning of this wall painting.

In the OM and FESEM images of sample B several layers are discernable (Figure 5a,b). The FESEM images and EDX analysis show that in sample B, the gold leaf was laid on a thicker $(10-20 \mu \mathrm{m})$ tin foil (Figure 5b). The EDX analysis reveals that the gold leaf consists of pure gold, within the detection limit of the method (Figure 5b). The layer below the metallic lamina, which contains mainly Fe and Ca, is the preparation layer. Layers, which appear dark both in the OM and FESEM images, are visible between the gold leaf and the tin lamina and the tin lamina and the preparation layer. The EDX spectra measured over these regions did not reveal the presence of other elements, besides carbon and oxygen. Thus, they probably correspond to the glue used for the adhesion of the metallic foils between them and to the preparation layer.

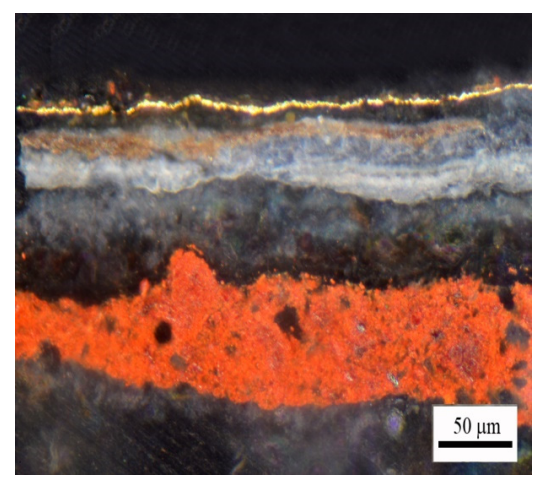

(a)

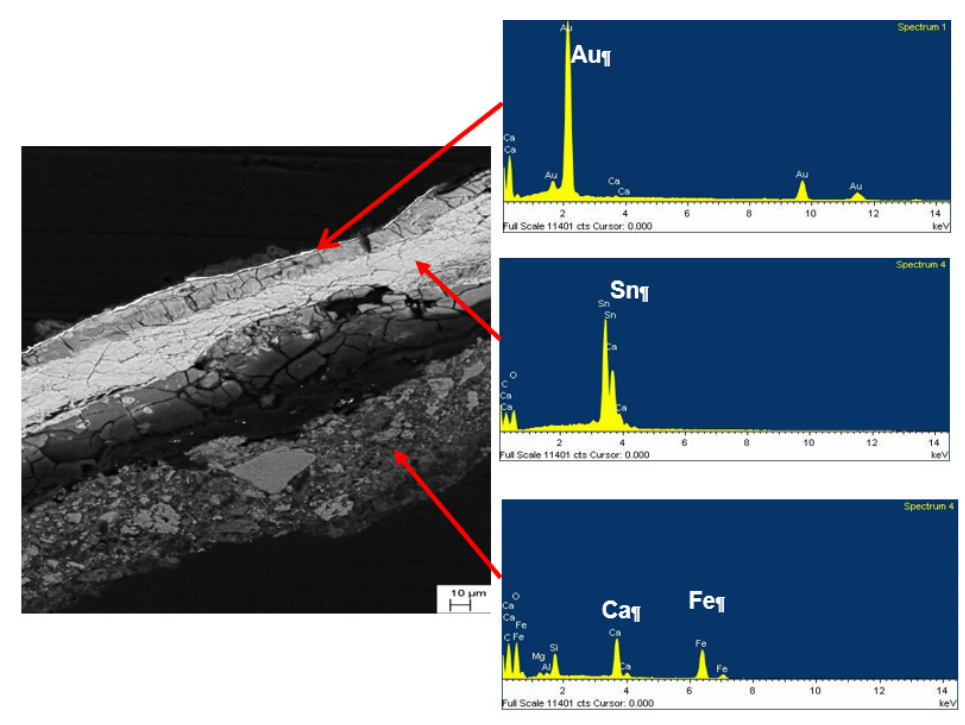

(b)

Figure 5. (a) OM image of sample B, reflected light, dark field. (b) FESEM image and EDX spectra of sample B (gold foil on tin lamina). The gold leaf is visible as a brighter, thin region on top of a thicker region corresponding to tin. (b) The EDX spectra measured on the gold leaf (spot analysis), on the tin lamina and on the preparation layer (analyzed area ca. $20 \times 20 \mu \mathrm{m}^{2}$ ).

The results of the ToF-SIMS analysis of sample B are similar to those of sample A, besides the presence of the peaks of the isotopes of $\operatorname{tin}(m / z 116.9,117.9,118.9$ and 119.9) (Figure 6a). The chemical maps of tin, silver and gold and their overlay are shown in Figure 6b. From the overlay map, it turns out that the signal of silver is localized mainly on the tin lamina. In addition, in this case silver is present in traces since it was not detected by EDX analysis. Although the analysis is limited to just one sample it should be noted that presence of silver impurities in the tin lamina could be used to derive information about the provenance of the material.

The analysis of samples A and B reveals residues of the last restoration carried out between 1989 and 1992. Barium, detected by EDX and ToF-SIMS ( $m / z$ 138), comes from consolidation treatments of the wall painting to transform calcium sulphate into barium sulphate. The ion fragments of fluorinated hydrocarbons $\left(\mathrm{m} / \mathrm{z} 50 \mathrm{CF}_{2}{ }^{+}, \mathrm{m} / z 69 \mathrm{CF}_{3}{ }^{+}, \mathrm{m} / z 119 \mathrm{C}_{2} \mathrm{~F}_{5}{ }^{+}\right.$etc.) observed in the ToF-SIMS spectra probably originate from previous restorations.

As far as the organic components are concerned, ToF-SIMS spectra measured for sample A in the region close to the gilding leaf show peaks which could be attributed to the acylium ions of palmitic $\left(\mathrm{C}_{16} \mathrm{H}_{31} \mathrm{O}^{+}, m / z 239\right)$ and stearic $\left(\mathrm{C}_{18} \mathrm{H}_{35} \mathrm{O}^{+} \mathrm{m} / z\right.$ 267) acids and to the ion fragments of monoglycerolester of palmitic $\left(\mathrm{C}_{19} \mathrm{H}_{37} \mathrm{O}_{3}{ }^{+} \mathrm{m} / z\right.$ 313) and stearic $\left(\mathrm{C}_{21} \mathrm{H}_{41} \mathrm{O}_{3}{ }^{+} \mathrm{m} / z\right.$ 341) acids. The peaks corresponding to 
the ion fragments of lead palmitate and stearate were also detected. Peaks ascribable to deprotonated palmitic and stearic acids were observed in the negative ion ToF-SIMS spectra. Palmitic and stearic acids are the oxidation and hydrolysis products of linseed and other unsaturated oils during ageing of the original materials, as shown in many studies on oil painting ageing [17]. On the other hand, linseed and other oils are not the only source of fatty acids, which are contained also in waxes and egg. Moreover, the presence of several contaminants and the altered state of the samples did not allow us to derive any firm conclusion about the nature of the adhesive materials.

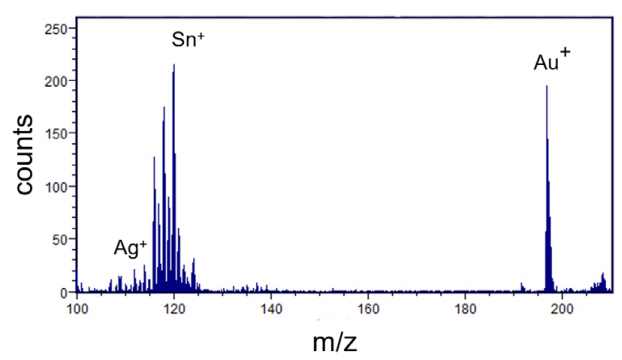

(a)
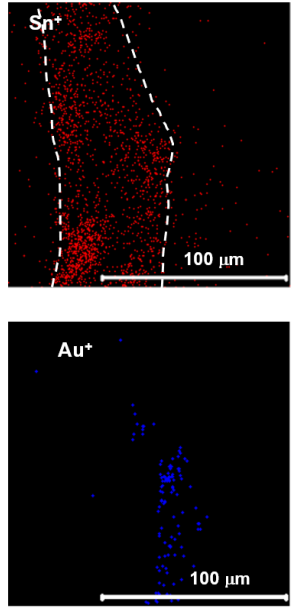

(b)
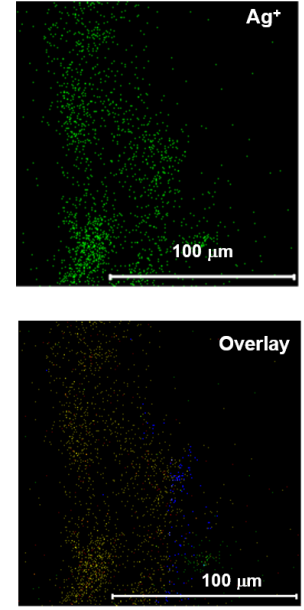

Figure 6. (a) ToF-SIMS mass spectrum for the $m / z$ regions of tin, silver and gold. (b) Maps showing total $\mathrm{Sn}^{+}$(red), $\mathrm{Ag}^{+}$(green) and $\mathrm{Au}^{+}$(blue) distributions. The dashed white line marks the zone of the Sn lamina. The overlay of the Sn, Ag and Au ion distributions is shown in the last image. The total count rates are 1904, 1797 and 115 for Sn, Ag and Au, respectively.

For sample B, in the ToF-SIMS spectra we did not observe peaks attributable to linseed oil or to protein-based materials. This is probably due to the alteration (mineralization) of the organic materials which occurs faster when they are directly in contact with air and light as a result of the partial detachment of the gold leaf from the oxidized tin foil.

\section{Conclusions}

The gilding decorations in the wall painting "La Maestà" by Simone Martini were characterized by a combination of microscopy and spectroscopy techniques. Because of the presence of contaminants and the altered state of the organic materials, the analysis by ToF-SIMS did not allow a univocal identification of the adhesive materials used to glue the gilding layers. The results of the EDX and ToF-SIMS analysis indicate that pure gold was used for gilding. ToF-SIMS revealed traces of silver in the gold leaf of the sample in which the gold leaf was directly attached to the preparation layer. For the sample in which a gold leaf was applied on a tin lamina, impurities of silver were detected mostly on the tin lamina.

Author Contributions: OM: XRD measurements: M.G. and A.S.; FESEM-EDX measurements: M.U. and A.A.; ToF-SIMS measurements: A.A., R.M.P. and N.M.; writing, review and editing of the manuscript: all authors.

Funding: This research was partially funded by MIUR, Grant "Dipartimento di Eccellenza 2018-2022" (Dipartimento DBCF) and by the PSR (Piano Sostegno alla Ricerca) 2018 grant (Dipartimento DFSTA).

Acknowledgments: The authors are grateful to Alessandro Terrosi (Dipartimento di Scienze Fisiche, della Terra e dell'Ambiente, University of Siena, Italy) and Claudia Faleri (Dipartimento di Scienze della Vita, University of Siena, Italy) for preparing the samples. The authors thank Marco Consumi (Dipartimento di Biotecnologia, Chimica e Farmacia, University of Siena, Italy) for the help with the measurements.

Conflicts of Interest: The authors declare no conflict of interest. 


\section{References}

1. Cennini, C. The Book of the Art of Cennino Cennini: A Contemporary Practical Treatise of Quattrocento Painting; George Allen and Uwin Ltd.: London, UK, 1922.

2. Marabelli, M.; Santopadre, P.; Ioele, M.; Cesareo, R.; Castellano, A.; Verità, M. Metal leaves utilized for decorations of Giotto's mural paintings. In "Bollettino d'Arte" Special Issue Dedicated to "Giotto in the Scrovegni Chapel: Materials Used in the Painting Technique"; Istituto Poligrafico e Zecca dello Stato: Rome, Italy, 2005; pp. 121-144.

3. Sandu, I.C.A.; Alfonso, L.U.; Murta, E.; de Sà, M.H. Gilding techniques in religious art between east and west, 14th-18th centuries. Int. J. Conserv. Sci. 2010, 1, 47-62.

4. Sandu, I.C.A.; De Sà, M.H.; Pereirac, M.C. Ancient 'gilded' art objects from European cultural heritage: A review on different scales of characterization. Surf. Interface Anal. 2011, 43, 1134-1151. [CrossRef]

5. Ingo, M.; Riccucci, C.; Pascucci, M.; Messina, E.; Giuliani, C.; Biocca, P.; Tortora, L.; Fierro, G.; Di Carlo, G. Combined use of FE-SEM+EDS, ToF-SIMS, XPS, XRD and OM for the study of ancient gilded artefacts. Appl. Surf. Sci. 2018, 446, 168-176. [CrossRef]

6. Osticioli, I.; Capozzoli, L.; Salvadori, B.; Banchelli, M.; Lavacchi, A.; Matteini, P.; Siano, S.; Gallo, L. The "oro di metà" Gilding in the Fifteenth-Century: A Multi-Analytical Investigation. Heritage 2019, 2, 1166-1175. [CrossRef]

7. Travaini, L.E. Coins, gold beaters and painters. How gold was used in wall paintings: Some examples from the Scrovegni Chapel. In "Bollettino d'Arte" Special Issue Dedicated to "Giotto in the Scrovegni Chapel: Materials Used in the Painting Technique"; Istituto Poligrafico e Zecca dello Stato: Rome, Italy, 2005; pp. 145-155.

8. Keune, K.; Hoogland, F.; Boon, J.J.; Peggie, D.; Higgit, C. Evalutation of the "added" value of SIMS: A mass spectrometry and spectroscopic study of an unusual Naples yellow oil paint reconstruction. Int. J. Mass Spectrom. 2009, 284, 22-34. [CrossRef]

9. Noun, M.; Van Elsande, E.; Touboul, D.; Glanville, H.; Buclow, S.; Walter, P.; Brunelle, A. High mass and spatial resolution mass spectrometry imaging of Nicolas Poussin painting cross section by cluster TOF-SIMS. J. Mass Spectrom. 2016, 51, 1196-1210. [CrossRef] [PubMed]

10. Biocca, P.; Santopadre, P.; Sidoti, G.; Sotgiu, G.; de Notaristefani, F.; Tortora, L. ToF-SIMS study of gilding technique in the fresco Vela della Castità by Giotto's school. Surf. Interface Anal. 2016, 48, 404-408. [CrossRef]

11. Atrei, A.; Benetti, F.; Potenza, M.; Dei, L.; Carretti, E.; Niccolucci, V.; Marchettini, N. Characterization of organic binders in a 13th century painted woodenpanel: Comparison of ToF-SIMS and Dot-ELISA results. Int. J. Mass Spectrom. 2018, 430, 63-68. [CrossRef]

12. Bagnoli, A. La Maestà di Simone Martini; Silvana: Rome, Italy, 1999.

13. Randon, V. La Maestà: Riflessioni preliminari sulla tecnica di un capolavoro. In Il Cantiere Della Maestà. Indagini Sulla Bottega di Simone Martini; Gavazzi, M., Giamello, M., Eds.; Quaderni del Museo Civico 4: Siena, Italy, 2018.

14. Mugnaini, S.; Bagnoli, A.; Bensi, P.; Droghini, F.; Scala, A.; Guasparri, G. Thirteen century wall paintings under the Siena Cathedral (Italy). Mineralogical and petrographic study of materials, painting techniques and state of conservation. J. Cult. Herit. 2006, 7, 171-185. [CrossRef]

15. Voras, E.Z.; de Ghetaldi, K.; Baade, B.; Gordon, E.; Gates, G.; Beebe, B.T. Comparison of oil and egg tempera paint systems using time-of-flight secondary ion mass spectrometry. Stud. Conserv. 2016, 61, 222-235. [CrossRef]

16. Garratt-Reed, A.J.; Bell, D.C. Energy Dispersive X-ray Analysis in the Electron, Microscope; BIOS Scientific Publishers: Oxford, UK, 2003.

17. Colombini, M.P.; Modugno, F. Organic Mass Spectrometry in Art and Archaelogy; Wiley: Hoboken, NJ, USA, 2009.

(C) 2019 by the authors. Licensee MDPI, Basel, Switzerland. This article is an open access article distributed under the terms and conditions of the Creative Commons Attribution (CC BY) license (http://creativecommons.org/licenses/by/4.0/). 